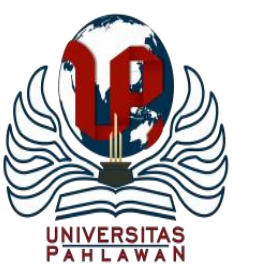

Jurnal Basicedu Volume 4 Nomor 3 Tahun 2020 Halm. 637 - 643

JURNAL BASICEDU

Research \& Learning in Elementary Education

https://jbasic.org/index.php/basicedu/index

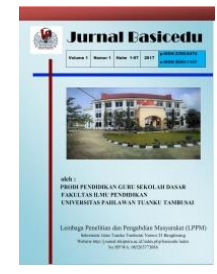

\title{
Kemampuan Membaca Permulaan Melalui Pendekatan Whole Language Di Sekolah Dasar
}

\author{
Siti Aisyah ${ }^{1,}$ Gusti Yarmi ${ }^{2}$, Mohamad Syarif Sumantri ${ }^{3}$, Vina Iasha ${ }^{4}$
}

Pendidikan Dasar, Pascasarjana, Universitas Negeri Jakarta ${ }^{1,3,4}$

Pendidikan Guru Sekolah Dasar, Fakultas Ilmu Pendidikan, Universitas Negeri Jakarta ${ }^{2}$

Email: sitiaisyah_pd14s2@mahasiswa.unj.ac.id ${ }^{1}$, gustiyarmi@ymail.com ${ }^{2}$, mohamadsumantri@ @mail.com ${ }^{3}$, vina.iasha@gmail.com ${ }^{4}$

\begin{abstract}
Abstrak
Tujuan dari penelitian ini adalah untuk memperoleh data secara empiris tentang pengaruh pendekatan pembelajaran whole language terhadap kemampuan membaca permulaan anak sekolah dasar kelas 1 SDN Guntur 03 Pagi, Setiabudi, Jakarta Selatan. Metode yang digunakan dalam penelitian yakni penelitian eksperimental yang menggunakan desain faktorial 2x2 dengan subjek anak kelas 1 SDN Guntur 03 Pagi, Setiabudi, Jakarta Selatan. Hasil penelitian ini menunjukkan bahwa terdapat pengaruh antara whole language terhadap kemampuan membaca permulaan anak Sekolah Dasar di Jakarta Selatan.
\end{abstract}

Kata kunci: whole language, membaca permulaan, sekolah dasar

\begin{abstract}
The research purposes to obtain empirical data on the implementation of whole language learning approach on the early reading ability of the first grade student at SD Negeri Guntur 03 Pagi, Setiabudi, South Jakarta. This is an experimental research with $2 x 2$ factorial design. The first grade students were sample of the research. The results of experiment indicated that the whole language learning approach affects students' early reading ability at SD Negeri Guntur 03 Pagi, Setiabudi, South Jakarta.
\end{abstract}

Keywords: Whole language Learning Approach, early Reading, Elementary school.

Copyright (c) 2020 Siti Aisyah, Gusti Yarmi, Mohamad Syarif Sumantri, Vina Iasha

Corresponding author :

Address : Jakarta Timur

ISSN 2580-3735 (Media Cetak)

Email : vina.iasha@gmail.com

ISSN 2580-1147 (Media Online)

Phone : 08211336657

DOI: https://doi.org/10.31004/basicedu.v4i3.393 


\section{PENDAHULUAN}

Membaca adalah salah satu dari empat keterampilan berbahasa, yaitu: keterampilan membaca, menulis, berbicara, mendengarkan. Setiap keterampilan tersebut erat sekali berhubungan dengan tiga keterampilan lainnya dengan cara yang beraneka ragam. Dalam memperoleh keterampilan berbahasa, kita biasanya melalui suatu hubungan urutan yang teratur: mulamula, pada masa kecil, kita belajar membaca dan menulis. Menyimak dan berbicara kita pelajari dari rumah, sementara membaca, dan menulis kita pelajari dari sekolah (Henry Guntur Tarigan, 2008). Membaca merupakan suatu proses yang memerlukan latihan secara rutin dan berkesinambungan. Untuk itu kemampuan membaca awal perlu dilatih di SD kelas awal (Irdawati, 2014). Membaca merupakan jendela dunia. Ungkapan ini secara jelas menggambarkan manfaat membaca, yaitu membuka, memperluas wawasan dan pengetahuan individu. Membaca membuat individu dapat meningkatkan kecerdasan, mengakses informasi dan juga memperdalam pengetahuan dalam diri seseorang (Handayani, Puji, 2020).

Banyak ditemukan di kelas-kelas awal ketika siswa sudah duduk di kelas II SD masih ada beberapa siswa yang mengalami kesulitan dalam proses membaca. Bahkan, membaca dasar melalui membaca nyaring masih dirasakan kesulitan oleh beberapa siswa yang memiliki keterbatasan. Oleh karenanya, perlu adanya inovasi proses pembelajaran yang optimal guna meningkatkan proses pembelajaran membaca permulaan pada siswa di kelas awal (kelas I SD) (Alfulaila, 2014). Hal tersebut cukup beralasan karena ketika siswa sudah menduduki kelas lanjut di kelas II SD, idealnya siswa sudah siap dalam hal kemampuan membacanya baik membaca dasar bahkan membaca lanjut dalam rangka mencari dan menemukan informasi secara tersurat maupun tersirat pada suatu teks sederhana.

Kemampuan membaca merupakan dasar untuk menguasai berbagai bidang studi (Dewi Mayangsari, 2014). Oleh karena itu, siswa harus belajar membaca agar ia dapat membaca untuk belajar. Membaca adalah kegiatan sehari-hari yang sering kita lakukan secara sadar atau tidak sadar melalui penguraian pesan yang mengelilingi kita dalam berbagai bentuk (Reni Gustiawati, Darnis Arief, 2020). Kemampuan membaca dilakukan agar peserta didik tidak hanya untuk mampu membaca tetapi peserta didik, melakukan kegiatan memahami karangan, bacaan, menanggapi teks bacaan, mengkomunikasikan secara lisan maupun tulisan, dan lain sebagainya.

Berdasarkan pelaksanaan proses pembelajaran yang dilakukan di kelas I SDN Guntur 03 Pagi, Setiabudi, Jakarta Selatan, kondisi yang sama ditemukan di kelas tersebut. Masih banyak diantara siswa yang mengalami kesulitan dalam membaca permulaan. Melalui membaca permulaan, tentunya akan dengan mudah siswa mengikuti kegiatan pembelajaran. Hasil yang cukup mengecewakan, selama proses pembelajaran baik mata pelajaran Bahasa Indonesia maupun mata pelajaran lainnya, proses membaca hampir tidak pernah tidak dilakukan oleh siswa. Seharusnya, jika memang benar pendekatan pembelajaran secara optimal dilakukan tidak ada siswa yang mengalami kesulitan terkait kemampuan membacanya. Hal tersebut dikarenakan proses habituasi melalui membaca yang dilakukan di kelas hampir setiap hari. Namun kenyataan yang ada tidak sesuai dengan apa yang diharapkan seharusnya, kondisi yang cukup disayangkan karena hampir $30 \%$ siswa di kelas awal tersebut masih mengalami kesulitan dalam proses membacanya atau dapat dikategorikan dalam 3 kelompok: (1) lancar; (2) belum lancar; 
(3) belum mampu. Yang mencengangkan adalah kelompok ketiga masih lebih dari $30 \%$ dari keseluruhan siswa di kelas I tersebut yang belum mampu membaca. Hal tersebut terindikasi dari beberapa siswa yang belum mampu mengenal huruf dengan sempurna, mengidentifikasi karakteristik dan perbedaan antar huruf secara alfabetis.

Mengembangkan kemampuan membaca permulaan pada siswa kelas awal tentunya memiliki tantangan tersendiri. Hal tersebut terkait bagaimana siswa dapat membaca permulaan dengan baik sesuai konsep yang diharapkan. Selain itu, pengenalan huruf menjadi faktor yang dominan bagi siswa yang baru pertama kali mengenal huruf dan karakteristiknya. Oleh karenanya, diperlukan setidaknya satu langkah yang cepat dan tepat agar siswa tidak kesulitan dalam mengenal dan mengerti huruf baik secara alfabetis maupun suku kata bahkan dalam bentuk kata. Banyak pendekatan yang bisa dipilih oleh guru untuk menciptakan suasana kelas yang kondusif, sarat dengan bahan bacaan, serta nyaman bagi anak untuk belajar (Marlina, 2015).

Kemampuan membaca permulaan anak dapat dikembangkan melalui belajar penemuan bebas dan belajar bermakna. Hal ini berdasar dari teori konstruktivisme dimana anak belajar melalui proses pengamatan, menemukan sendiri, dan mengkonstruksikan pengetahuan yang diperolehnya (Mufiidah, D. W., Haenilah, E. Y., \& Sofia, 2019). Hal ini sejalan dengan pendapat menurut Cooper dalam (Rusman, 2017) bahwa konstruktivis memandang anak dapat menginterpretasi informasi dan dunia sesuai dengan realitas personal mereka, dan mereka belajar melalui observasi, proses, dan interpretasi dan membentuk informasi tersebut ke dalam pengetahuan personalnya. Maka dari itu, kemampuan membaca permulaan anak harus dikembangkan dengan alternative pendekatan, model ataupun media yang dilakukan oleh guru agar dapat tereksplorasi kemampuan dari peserta didik.

Sikap manusia memiliki dua bentuk kemampuan berbahasa, yaitu tulisan dan lisan. Keduanya dibedakan lagi menjadi dua, yaitu: kemampuan reseptif (menyimak dan membaca) dan produktif (berbicara dan menulis) (Mohammad Syarif Sumantri, 2016). Untuk dapat mengimplementasikan pembelajaran dengan maksimal maka guru harus menggunakan pendekatan atau model-model yang efektif dan sesuai dengan pembelajaran (Vina Iasha, 2018). Salah satu pendekatan pembelajaran yang sesuai adalah pendekatan terpadu dalam pembelajaran bahasa dilandasi pandangan bahasa holistic (whole language) yang memperlakukan bahasa sebagai sesuatu yang bulat dan utuh. Pada hakikatnya whole language merupakan falsafah pandangan atau keyakinan tentang hakikat belajar dan bagaimana anak belajar secara optimal (V. Froese, 1991).

Satu alternatif langkah inovatif yang dapat dilakukan adalah melalui pendekatan whole language. Whole language adalah suatu pendekatan pembelajaran bahasa yang menyajikan pengajaran bahasa secara utuh, tidak terpisah-pisah (Goodman, K.S., 1986; Weaver, 1990). Sedangkan whole language telah dikenal sebagai salah satu pendekatan pembelajaran, sebuah sistem kepercayaan tentang sifat pembelajaran dan bagaimana hal itu dapat dipupuk di kelas dan sekolah. Pendekatan whole language merupakan suatu pendekatan dalam pembelajaran bahasa yang diajarkan secara holistik, utuh, tidak terpisah-pisah antara keempat keterampilan berbahasa, yaitu mendengarkan, berbicara, membaca, dan menulis. Dalam proses pembelajaran selalu memadukan keempat keterampilan berbahasa tersebut dan 
diharapkan selama proses pembelajaran dapat berpengaruh terhadap membaca anak (Nehru Meha dan Adiyati Fathu Roshonah, 2015).

The whole language proponents claimed that language should not be broken down into letters and combinations of letters and decoded (Stahl \& Miller, 1989). Instead, they believe that language is a complete system of making meaning, with words functioning in relation to each other in context (Moats, 2007). (V. Froese, 1991). Defines whole language as a child centered, literaturebased approach to language teaching that immerses students in real communication situations whenever possible.

Dalam kelas whole language akan dipenuhi barang cetak, siswa belajar secara aktif, siswa bekerja dan belajar sesuai kemampuan, guru berperan sebagai contoh, dan fasilitator. Suasana kelas dibuat senyaman mungkin sehingga diharapkan dapat memudahkan siswa untuk membaca. Selain itu, dengan pendekatan whole language diharapkan dapat menumbuhkan kemampuan dan keaktifan membaca siswa baik saat reading aloud, sustained silent reading, share reading, guide reading, maupun independent reading.

Proses pembelajaran Bahasa Indonesia untuk mengembangkan kemampuan berbahasa khususnya aspek membaca menjadi satu prioritas yang harus dioptimalkan di kelas awal. Hal tersebut akan berimplikasi pada proses pembelajaran yang dilakukan. Proses pembelajaran harus berafiliasi pada proses membaca untuk mengoptimalkan kemampuan membaca yang perlu dikembangkan dan ditingkatkan juga berdasarkan perkembangan siswa. Hal tersebut dipertegas pada teori tahap perkembangan peserta didik menurut Piaget dalam William Crain menyatakan bahwa periode I pada usia 0-2 tahun pada tingkat sensori motorik, periode II pada usia 2-7 tahun pada tingkat pra-operasional, periode III pada usia 7-11 tahun pada tingkat operasi konkret, dan periode IV pada usia 11 tahun ke atas sudah tingkat operasi formal (Dixon, L. Q., \& Wu, 2014). Oleh karenanya, perlu dipertimbangkan berbagai hal yang dapat digunakan untuk meningkatkan kemampuan membaca permulaan pada siswa awal.

Berasumsi dari pemaparan mendalam terkait proses pembelajaran Bahasa Indonesia khususnya pengembangan dan peningkatan kemampuan membaca permulaan sangatlah urgent hubungannya dengan kemampuan lanjut yang harus dikuasai oleh siswa di SD. Oleh karenanya, berbekal permasalahan krusial terkait kemampuan membaca permulaan di SD di Jakarta Selatan perlu adanya perbaikan proses pembelajaran. Satu alternatif tindakan telah dipilih untuk dapat digunakan dalam rangka optimalisasi kemampuan membaca permulaan pada siswa kelas I Sekolah Dasar di Jakarta. Satu alternatif tindakan yang dipilih yaitu melalui optimalisasi penggunaan pendekatan pembelajaran whole language. Melalui pendekatan whole language yang dimodifikasi dan olah proses pembelajaran yang inovatif diharapkan dapat digunakan untuk meningkatkan kemampuan membaca permulaan pada siswa kelas I Sekolah Dasar.

\section{METODE}

Metode dalam penelitian ini menggunakan metode eksperimen dengan desain $2 \times 2$ faktorial. Subjek dalam penelitian ini siswa kelas 1 Guntur 03 Pagi, Setiabudi, Jakarta Selatan. Adapun sumber data yang diperoleh berasal dari catatan lapangan dan dokumentasi. Pada teknik analisis data peneliti menggunakan dua teknik yakni pertama teknik analisis data secara desktiptif dan yang kedua analisis data secara kualitatif. 


\section{HASIL DAN PEMBAHASAN}

Hasil penelitian yaitu mencari tahu besarnya pengaruh antara variable dependen terhadap independen. Sebelum diuji hipotesis data penelitian ini diuji normalitasnya dengan tujuan untuk melihat apakah setiap variabel terdistribusi secara normal atau tidak. Berikut ini adalah hasil uji normalitas dalam penelitian ini.

Tabel 1. Uji Normalitas One-Sample KolmogorovSmirnov Test

\begin{tabular}{lccccc}
\hline & $\begin{array}{c}\text { Test } \\
\text { Statistic }\end{array}$ & $\mathrm{N}$ & Mean & $\begin{array}{c}\text { Std. } \\
\text { Deviation }\end{array}$ & $\begin{array}{c}\text { Asymp. Sig. } \\
\text { (2-tailed) }\end{array}$ \\
\hline $\begin{array}{l}\text { teacher } \\
\text { certification }\end{array}$ & .183 & 100 & 61.33 & 7.436 &, 105 \\
Teaching Ability & .150 & 100 & 81.12 & 6.652 &, 200 \\
\hline
\end{tabular}

Berdasarkan hasil uji normalitas data penelitian, diperoleh nilai signifikansi $>0,05$. Hal ini menunjukkan bahwa data penelitian ini terdistribusi dengan normal. Selanjutnya uji hipotesis dalam penelitian ini adalah untuk melihat apakah variabel $X$ memiliki peran terhadap variabel Y. Dalam hal ini peneliti ingin melihat pengaruh whole language terhadap membaca permulaan siswa sekolah dasar di Jakarta. Pengujian hipotesis dilakukan dengan analisis regresi sederhana. Berdasarkan hasil pengujian tersebut didapat hasil sebagai berikut.

Tabel 2. Uji Regresi Variable Whole Language Terhadap Membaca Permulaan di Sekolah Dasar.

\begin{tabular}{cccc}
\hline R Square & F & Sig & Regression Equation \\
\hline, 120 & 13.305 &, 000 & $Y=62.152-0,309 \mathrm{X}$ \\
\hline
\end{tabular}

Hasil dari perhitungan yang dilakukan, diperoleh hasil pengaruh whole language terhadap kemampuan membaca permulaan anak sekolah dasar di Jakarta $(F=13.305, p=0,000)$. Sehingga hipotesis penelitian ini diterima. Selain itu diketahui nilai koefisien determinasi sebesar 0,120. Besarnya nilai koefisien determinasi menunjukkan besaran peran dalam persen, yaitu $12,0 \%$. Sehingga dapat disimpulkan bahwa pengaruh whole language terhadap kemampuan membaca permulaan anak $12,0 \%$, dimana $88 \%$ lainnya dipengaruhi faktor lain. Selanjutnya, berdasarkan tabel diatas juga diperoleh persamaan linear $Y=62.152-0,309 X$. Hal tersebut menunjukkan bahwa setiap penambahan 1 nilai pada whole language, maka nilai pada kegiatan akan berkurang sebesar 0,309.

Kemampuan membaca permulaan dengan mengikuti sintaks pendekatan whole language, yaitu: tahap persiapan (kegiatan pendahuluan), tahap pelaksanaan (kegiatan inti pada eksplorasi), tahap evaluasi menyeluruh (kegiatan inti pada konfirmasi) memberikan kebebasan siswa dalam mengintegrasikan seluruh keterampilan berbahasa (menyimak, berbicara, membaca, menulis) terhadap materi yang disajikan dalam pembelajaran. Pendekatan pembelajaran whole language erat hubungannya dengan materi membaca permulaan siswa kelas rendah $(1,2,3)$ pada pembelajaran Bahasa Indonesia. Guru dapat mengintegrasi seluruh keterampilan berbahasa dan materi pembelajaran yang dapat ditampilkan melalui video pembelajaran yang dapat ditayangkan secara berulang-ulang sehingga pembelajaran menjadi menyenangkan. Pembelajaran yang dilakukan di kelas eksperimen maupun kontrol tidak dibedakan dari segi materi maupun sumber belajarnya. Kelas eksperimen maupun kontrol sama-sama dibelajarkan dengan materi mengenal huruf dengan sempurna, mengidentifikasi karakteristik dan perbedaan antar huruf secara alfabetis. Dengan mempergunakan sumber belajar baik buku maupun LKS dibuat sama, namun karena teknik yang dipergunakan dalam menyampaikan materi mengenal huruf 
dengan sempurna, mengidentifikasi karakteristik dan perbedaan antar huruf secara alfabetis berbeda, hal tersebut mempengaruhi hasil belajar siswa. Pembelajaran konvensional membuat siswa jenuh dan bosan dalam pembelajaran karena sebagian besar waktu dihabiskan untuk mendengarkan, mencatat dan mengerjakan soal secara individu. Pendekatan pembelajaran whole language berbantuan video pembelajaran memberikan pengaruh yang lebih baik dibandingkan dengan model pembelajaran konvensional. Dari simpulan tersebut ada suatu perbedaan yang terlihat selama penelitian berlangsung. Perbedaan tersebut adalah kelompok eksperimen yang dibelajarkan dengan pendekatan pembelajaran whole language berbantuan video pembelajaran yang memiliki skor rata-rata hasil belajar yang lebih besar dari kelompok kontrol yang dibelajarkan dengan pembelajaran konvensional. Secara operasionalnya pendekatan pembelajaran whole language berbantuan video pembelajaran dan pembelajaran konvensional digunakan untuk materi pembelajaran yang sama tetapi dengan cara penyampaian yang berbeda.

Pendekatan whole language didasarkan pada interaksi sosial. Kegiatan belajarnya adalah kebanyakan dilakukan oleh siswa, karena pendekatan ini bukan mengajarkan cara belajar bahasa, tetapi lebih kepada cara berbicara yang baik dan komunikatif. Ini akan membuat proses belajar menjadi terpusat pada siswa yang menjadikan pembelajaran bermakna. Therefore, the whole language approach in addition to having a holistic paradigm, but also student's centered (Gilles, 2006). To build social interaction requires collaborative learning. Collaboration among fellow students helps them to build their language mastery by representing each other's cultures, their experiences, so that they become rich in vocabulary, and it strengthen their language and communication skills (Dixon, L. Q., \& Wu, 2014).

\section{KESIMPULAN}

Berdasarkan hasil temuan penelitian dapat terlihat adanya peningkatan pada kemampuan membaca permulaan tema berbagai kegiatanku, subtema kegiatan pagi hari melalui pendekatan whole language pada siswa kelas I yang dilaksanakan di SDN Guntur 03 Pagi, Setiabudi, Jakarta Selatan. Hal ini dapat terlihat dari refleksi tes kemampuan membaca permulaan pada siklus I dan siklus II.

\section{REFERENSI}

Alfulaila, N. (2014). Pengaruh Pendekatan Whole Language Terhadap Hasil Belajar Membaca Pemahaman Bahasa Indonesia Siswa Kelas IV SD. Jurnal Dikdas.

Dewi Mayangsari. (2014). Peningkatan Kemampuan Membaca Permulaan Kelas I SD Mardi Putera Surabaya Dengan Menggunakan PAKEM (Pembelajaran yang Aktif, Kreatif, Efektif, dan Menyenangkan). 1 No 1.

Dixon, L. Q., \& Wu, S. (2014). Understanding Language Learning: Interaction Model in Foreign Language Contexts. Malaysian Journal of Learning and Instruction, 11, 23-39.

http://mjli.uum.edu.my/images/pdf/11 mjli/ 2understandingg.pdf

Goodman, K.S., dkk. (1986). Language Thinking in School: A Whole Language Curriculum. NY: Richard C. Owens.

Handayani, Puji, dkk. (2020). Pengembangan media komik untuk meningkatkan minat membaca siswa sekolah dasar. Jurnal Basicedu, 4 No 2. https://doi.org/25801147

Henry Guntur Tarigan. (2008). Membaca. Angkasa.

Irdawati. (2014). Meningkatkan Kemampuan Membaca Permulaan Dengan Menggunakan Media Gambar Kelas 1 di Min Buol. Jurnal Kreatif Tadulako Online 
643 Kemampuan Membaca Permulaan Melalui Pendekatan Whole Language di Sekolah Dasar- Siti Aisyah, Gusti Yarmi, Mohamad Syarif Sumantri, Vina Iasha

DOI: https://doi.org/10.31004/basicedu.v4i3.393

Vol.5 No.4, 5(No. 4).

Marlina. (2015). Meningkatkan Kemampuan Membaca Permulaan Dengan Menggunakan Metode SAS Siswa Kelas I SDN Ambunu Kecamatan Bungku Barat Kabupaten Morowali. Jurnal Kreatif Tadulako Online Vol.5 No.4, 2 No 1.

Moats, L. (2007). Whole language high jinks: How to Tell When "Scientifically-Based Reading Instruction” Isn't.

Mohammad Syarif Sumantri. (2016). Model Pembelajaran Terpadu Di Sekolah Dasar. Raja Grafindo Persada.

Mufiidah, D. W., Haenilah, E. Y., \& Sofia, A. (2019). Pembelajaran Berbantuan ICT dengan Kemampuan Membaca Permulaan Anak. Jurnal Pendidikan Anak, 5(1).

Nehru Meha dan Adiyati Fathu Roshonah. (2015). Implementasi Whole Language Approach Sebagai Pengembangan Model Pembelajaran Berbahasa Awal Anak Usia 5-6 Tahun di Paud NonFormal. Jurnal Pendidikan, 15 No 2, 73.

Reni Gustiawati, Darnis Arief, A. Z. (2020). Pengembangan bahan ajar membaca permulaan dengan menggunakan cerita fablepada siswa sekolah dasar. Jurnal Basicedu, $\quad 4 \quad$ No 2. https://jbasic.org/index.php/basicedu/articl e/view/339/pdf

Rusman. (2017). Belajar dan Pembelajaran: Berorientasi Standar Proses Pendidikan. Kencana.

V. Froese. (1991). Whole Language Practice and Theory. Allyn \& Bacon.

Vina Iasha. (2018). Peningkatan Proses Pembelajaran Tematik Terpadu Menggunakan Pendekatan Scientific di Sekolah Dasar. AR-RIAYAH. Jurnal Pendidikan Dasar, 2(1), 17-36.

Weaver, C. (1990). Understanding Whole Language (From Principles to Practice). Irwin Publishing. 